\title{
The use of comparative effectiveness research to inform policy decisions on the inclusion of bevacizumab for the treatment of macular diseases in Thailand's pharmaceutical benefit package
}

This article was published in the following Dove Press journal:

ClinicoEconomics and Outcomes Research

5 December 2012

Number of times this article has been viewed

\section{Thunyarat Anothaisintawe $e^{1,2}$ \\ Pattara Leelahavarong' \\ Tanapat Ratanapakorn ${ }^{3}$ \\ Yot Teerawattananon' \\ 'Health Intervention and Technology Assessment Program, Ministry of Public Health, Nonthaburi, Thailand; ${ }^{2}$ Family Medicine Department and Section of Clinical Epidemiology and Biostatistics, Ramathibodi Hospital, Mahidol University, Bangkok, Thailand; ${ }^{3}$ Department of Ophthalmology, Khon Kaen Univerity, Khon Kaen, Thailand}

Correspondence: Yot Teerawattananon Health Intervention and Technology Assessment Program, 6th Floor, 6th building, Department of Health, Ministry of Public Health, Tiwanon Road, Amphur Muang, Nonthaburi, Thailand

Tel +66 25904374

Fax +66 25904369

Email yot.t@hitap.net

\begin{abstract}
There is increasing impetus to use pharmaceutical interventions, ie, ranibizumab or bevacizumab, for the treatment of particular macular diseases. This paper describes the evidence and decision-making of the National List of Essential Medicines Committee that recently announced the inclusion of bevacizumab for the treatment of macular diseases in its pharmaceutical benefit package. The findings of a systematic review and meta-analysis in this paper indicate that the intravitreal administration of bevacizumab is superior to nonpharmaceutical treatments for age-related macular degeneration (AMD) and diabetic macular edema (DME), but inconclusive for retinal vein occlusion, given the limited evidence. The study also failed to distinguish among the differences in terms of visual acuity improvement, reduction of central macular thickness, and response to treatment between AMD and DME patients treated with bevacizumab and those treated with ranibizumab. Although bevacizumab was not licensed for AMD and DME, the committee decided to include bevacizumab in the National List of Essential Medicines. It is expected that many patients who are in need of treatment but who are unable to afford the expensive alternative drug, ranibizumab, will be able to receive this effective treatment instead and be prevented from suffering irreversible loss of vision. At the same time, this policy will help generate evidence about the real-life effectiveness and safety profiles of the drug for future policy development in Thailand and other settings.
\end{abstract}

Keywords: bevacizumab, macular degeneration, diabetic macular edema, retinal vein occlusion, comparative effectiveness research

\section{Introduction}

Universal health-care coverage has been available in Thailand since 2003, meaning that the Royal Thai Government ensures the universal access of essential health-care services for the country's 67 million people. ${ }^{1}$ This is achieved via the National List of Essential Medicines (NLEM), a national drug list that is used as a reference for the pharmaceutical benefit package for all public health insurance schemes. ${ }^{2}$ All patients who meet the medical criteria are entitled to receive the free medications listed in the NLEM. Continuously developed by a subcommittee with extensive support from clinical experts and public research institutes, this list currently covers more than 800 drug formularies. ${ }^{3}$ Since its establishment in 2006, the Health Intervention and Technology Assessment Program (HITAP), which is a national health-technology 
assessment agency, has played a part in the development of the NLEM. ${ }^{4}$ In 2011, the subcommittee requested that HITAP investigate the clinical efficacy/effectiveness and safety of bevacizumab and ranibizumab compared with other nonpharmaceutical interventions for the treatment of age-related macular degeneration (AMD), diabetic macular edema (DME), and retinal vein occlusion (RVO). The request was based on the fact that there were no medications in the NLEM available for the treatment of these diseases, even though several empirical studies indicated significant benefits of pharmaceutical interventions. ${ }^{5-11}$ This resulted in the inaccessibility of the drugs for patients who cannot afford these proven medicines. Therefore, the aim of this study is to inform the NLEM subcommittee in order to further refine the NLEM via the analysis of the study's results and the policy implications. The findings from this paper can also be used as policy input in other settings with similar interests in including pharmaceutical treatments for AMD, DME, and RVO.

\section{The country context}

Thailand is regarded as one of the countries whose population is aging most rapidly. The proportion of people aged 65 years or older is expected to double over the 20-year period of 2010-2030, with $8.7 \%$ of the total population in this category in 2010 compared to a projected $17.4 \%$ in $2030 .{ }^{12}$ As the population continues to age, visual impairment is expected to rise, leading to a substantial decline in the quality of life among this demographic. AMD, DME, and RVO are among the major causes of irreversible and profound loss of vision in the Thai population. The prevalence of AMD and RVO is currently $0.3 \%{ }^{13}$ and $0.5 \%-2 \%{ }^{14}$ of the total population, respectively. Meanwhile, the prevalence of DME has been reported at about $2 \%-3 \%$ in Thai diabetic patients. ${ }^{15}$

Bevacizumab has been licensed in Thailand for the treatment of metastatic cancer of the colon and rectum, while ranibizumab has been approved for the treatment of wet AMD. However, bevacizumab has been widely used off-license in Thailand for the treatment of AMD, DME, and RVO due to its much lower cost (1200 baht/dose) compared to ranibizumab (54,000 baht/dose). Since neither of these drugs is listed in the NLEM, most of the patients treated with bevacizumab or ranibizumab need to shoulder the cost of the treatment by themselves. Furthermore, the recent legal challenge by a pharmaceutical company against local health authorities in England raises serious concern among Thai clinical experts over the use of off-license bevacizumab. ${ }^{16-18}$

\section{Evidence generation}

A comparative effectiveness study was performed by a research team comprising HITAP researchers and members of the Thai Retina Society, which is a part of the Royal College of Ophthalmologists of Thailand. Detailed information of the methods used for this study is described in Supplementary methods. A systematic review and meta-analysis of relevant randomized controlled trials retrieved from Medline and Scopus up to December 19, 2011 was carried out. Studies assessing the clinical outcomes of bevacizumab, ranibizumab, or nonpharmaceutical interventions for AMD, DME, or RVO patients were eligible for inclusion in the review. The outcomes of interest were central macular thickness (CMT) and visual acuity (VA), which is usually quantified by an Early Treatment Diabetic Retinopathy Study (ETDRS) letter score, logarithm of the minimum angle of resolution $(\log$ MAR), or Snellen fraction. An interesting outcome was the number of patients who responded positively to the treatment, which was commonly defined by an improvement in VA equal to or greater than ten or 15 letters of ETDRS or an improvement in VA equal to or greater than two lines of $\log$ MAR. A flowchart of the study selection process is presented in Figure S1, while the basic characteristics of the included studies are shown in Tables S1-S3.

\section{Key findings}

Table 1 summarizes the results of the meta-analysis in terms of the treatment effects of bevacizumab, ranibizumab, and nonpharmacological interventions in AMD, DME, and RVO patients. For AMD, four studies ${ }^{19-22}$ reported the treatment response rate of bevacizumab and PDT. Among these four studies, two studies ${ }^{21,22}$ defined treatment response as an increase of 15 ETDRS letters, while another study conducted by Bashshur et al ${ }^{19}$ defined treatment response as an increase of three lines in the Snellen fraction, and a study conducted by Lazic and Gabric ${ }^{20}$ defined treatment response as an increase of 0.2 in $\log$ MAR. Compared to those treated with PDT, AMD patients treated with bevacizumab were shown to be 3.44 times (95\% confidence interval [CI] 1.67-7.10) more likely to respond to the treatment (Table 1, Figure 1A, and Table S4). When comparing ranibizumab with bevacizumab in AMD patients, the treatment response rates for these two treatments were not significantly different, with a pooled relative risk (RR) of 0.91 (95\% CI 0.71 to 1.16$)$, as shown in Table 1, Figure 1B and Table S5. Four studies ${ }^{23-26}$ found that when compared with bevacizumab, ranibizumab could improve VA and decrease CMT in AMD patients. However, these differences did not reach statistical significance. 
Table I Summary of all treatment comparisons for age-related macular degeneration, diabetic macular edema, and retinal vein occlusion

\begin{tabular}{|c|c|c|c|}
\hline Treatment & $\begin{array}{l}\text { Visual acuity } \\
\text { (USMD with 95\% CI) }\end{array}$ & $\begin{array}{l}\text { Central macular thickness } \\
\text { (USMD with } 95 \% \mathrm{CI} \text { ) }\end{array}$ & $\begin{array}{l}\text { Response to treatment } \\
\text { (RR with } 95 \% \mathrm{Cl} \text { ) }\end{array}$ \\
\hline \multicolumn{4}{|l|}{ Age-related macular degeneration } \\
\hline Bevacizumab vs PDT ${ }^{19-22}$ & NA & NA & $3.44(1.67$ to 7.10$)$ \\
\hline Ranibizumab vs bevacizumab ${ }^{23-26}$ & $0.49(-1.37$ to 2.34$)$ & $-14.18(-32.06$ to 3.70$)$ & 0.91 (0.7I to I.I6) \\
\hline \multicolumn{4}{|l|}{ Diabetic macular edema } \\
\hline Bevacizumab vs photocoagulation ${ }^{27-31}$ & 5.44 (0.05 to 10.83$)$ & 23.61 ( -2.78 to 50.00$)$ & $2.40(1.14$ to 5.05$)$ \\
\hline Ranibizumab vs bevacizumab 27-30,45-46 & $5.12(-17.50$ to 27.75$)$ & $-51.57(-169.84$ to 66.69$)$ & $1.02(0.52 \text { to } 1.99)^{\mathrm{a}}$ \\
\hline \multicolumn{4}{|l|}{ Retinal vein occlusion } \\
\hline Bevacizumab vs sham ${ }^{32,47-49}$ & $8(-5.26 \text { to } 21.26)^{\mathrm{a}}$ & NA & NA \\
\hline Ranibizumab vs sham ${ }^{32,47,48}$ & $11.39(9.27$ to $13.5 \mathrm{I})$ & NA & NA \\
\hline Ranibizumab vs bevacizumab ${ }^{32,47-49}$ & $3.39(-10.55 \text { to } 17.33)^{\mathrm{a}}$ & NA & NA \\
\hline
\end{tabular}

Note: apooling from network meta-analysis.

Abbreviations: $\mathrm{Cl}$, confidence interval; NA, not applicable because of insufficient data for pooling; PDT, photodynamic therapy; RR, relative risk; USMD, unstandardized mean difference.

The unstandardized mean differences (USMDs) of VA and CMT between AMD patients receiving ranibizumab compared with bevacizumab were 0.49 ETDRS letters ( $95 \% \mathrm{CI}-1.37$ to $2.34)$ and $-14.18 \mu \mathrm{m}(95 \% \mathrm{CI}-32.06$ to 3.70$)$, respectively (see Table 1, Figure 1C, and Table S6).

For DME, three studies ${ }^{27-29}$ showed a significant benefit of bevacizumab over photocoagulation in terms of treatment response rate. As indicated in Table 1, Figure 2A, and Table S7, the pooled RR of treatment response rate was 2.40 (95\% CI 1.14 to 5.05), which means that DME patients receiving bevacizumab had a 2.4 -fold higher chance of responding positively to treatment compared with patients receiving photocoagulation. Four studies ${ }^{27,29-31}$ compared bevacizumab and photocoagulation with respect to VA and CMT changes in DME patients. The results from these four studies revealed a significant effect of bevacizumab on improving VA, but failed to show any significant effect of bevacizumab on decreasing CMT when compared with photocoagulation with USMDs of VA and CMT equal to 5.44 ETDRS letters (95\% CI 0.05 to 10.83$)$ and $23.61 \mu \mathrm{m}(95 \%$ CI -2.78 to $50.00 \mu \mathrm{m}$ ), respectively (see Table 1, Figure 2B and C, and Table S8). Since there was no study that made a
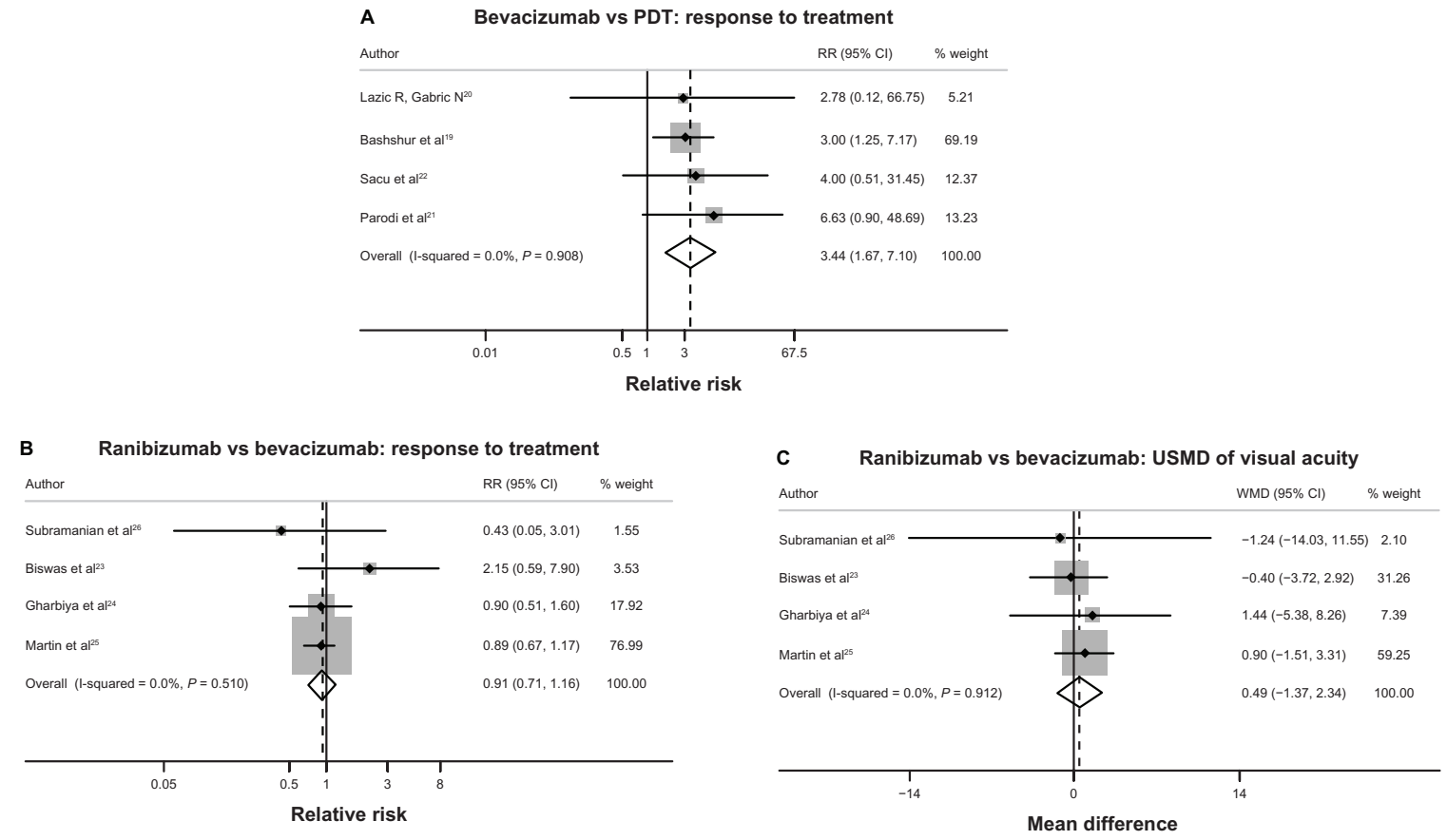

Figure I (A-C) Forest plots of pooled treatment effects for all treatment comparisons in age-related macular degeneration.

Abbreviations: PDT, photodynamic therapy; RR, relative risk; Cl, confidence interval; USMD, unstandardized mean difference; WMD, weighted mean difference. 

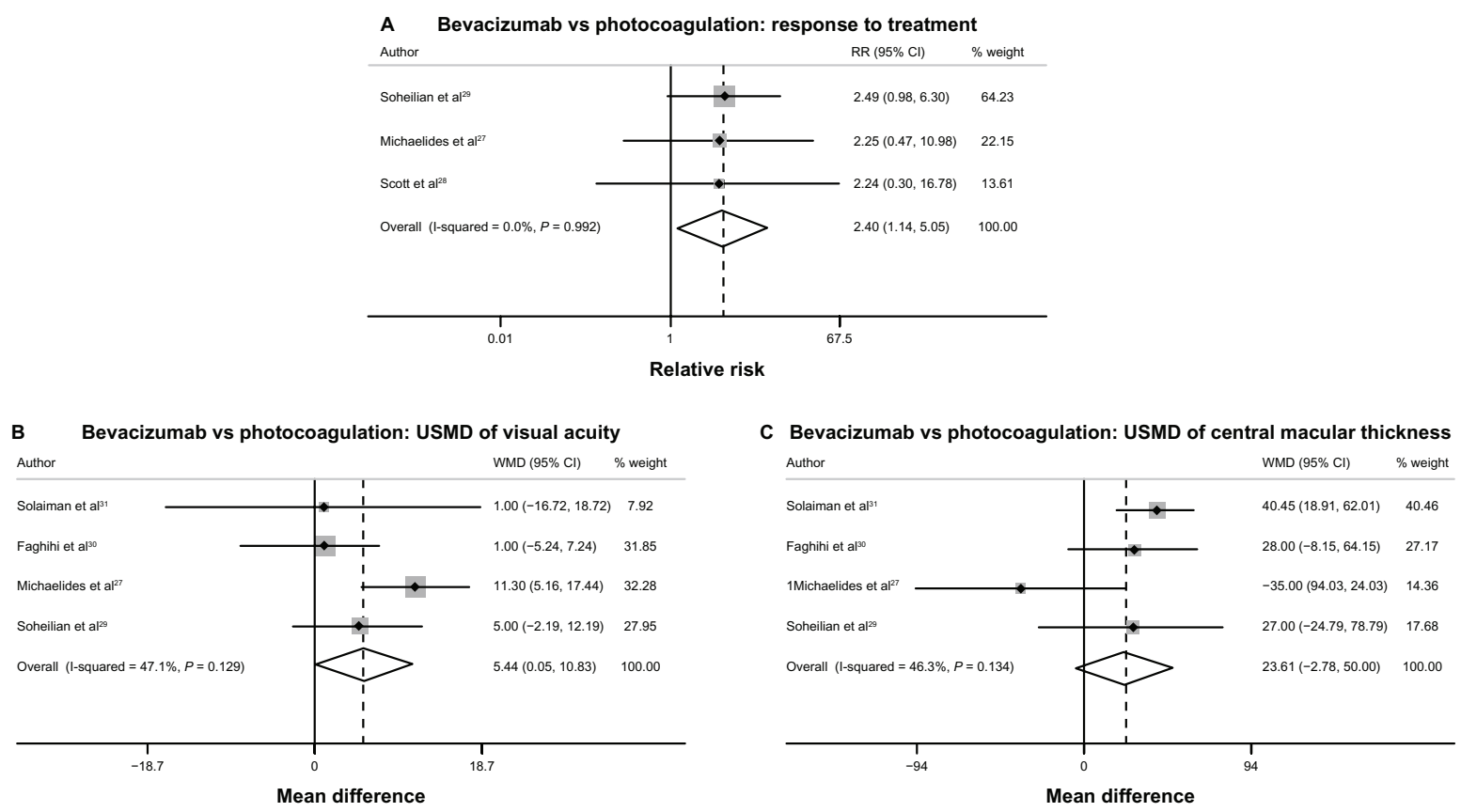

Figure 2 (A-C) Forest plots of pooled treatment effects of bevacizumab compared with photocoagulation treatment in diabetic macular edema. Abbreviations: RR, relative risk; Cl, confidence interval; USMD, unstandardized mean difference; WMD, weighted mean difference.

direct comparison between bevacizumab and ranibizumab in DME patients, network meta-analysis was then applied for estimating the treatment differences between bevacizumab and ranibizumab. Results from the network meta-analysis show that the treatment effect of ranibizumab was not significantly better than the treatment effect of bevacizumab in terms of VA change, CMT change, and treatment response rate. The pooled RR of response rate and USMD of VA and CMT between ranibizumab and bevacizumab were 1.02 (95\% CI 0.52-1.99), 5.12 ETDRS letters (95\% CI -17.50 to 27.75), and $-51.57 \mu \mathrm{m}(95 \% \mathrm{CI}-169.84$ to 66.69$)$, respectively (see Table 1, and Figures S2-S4).
For RVO, only the comparison between ranibizumab and sham according to mean VA change had sufficient data for pooling. Pooling the mean VA changes from three studies $^{32,47,48}$ revealed the significant benefit of ranibizumab over sham for treating RVO, with a USMD equal to 11.39 ETDRS letters (95\% CI 9.27 to 13.51), as seen in Table 1, Figure 3, and Table S9.

For comparison between bevacizumab with sham and bevacizumab with ranibizumab, the results from the network metaanalysis showed no significant difference between these two alternatives in terms of VA change. The USMDs of VA change between bevacizumab with ranibizumab and bevacizumab

\section{Ranibizumab vs sham: USMD of visual acuity}

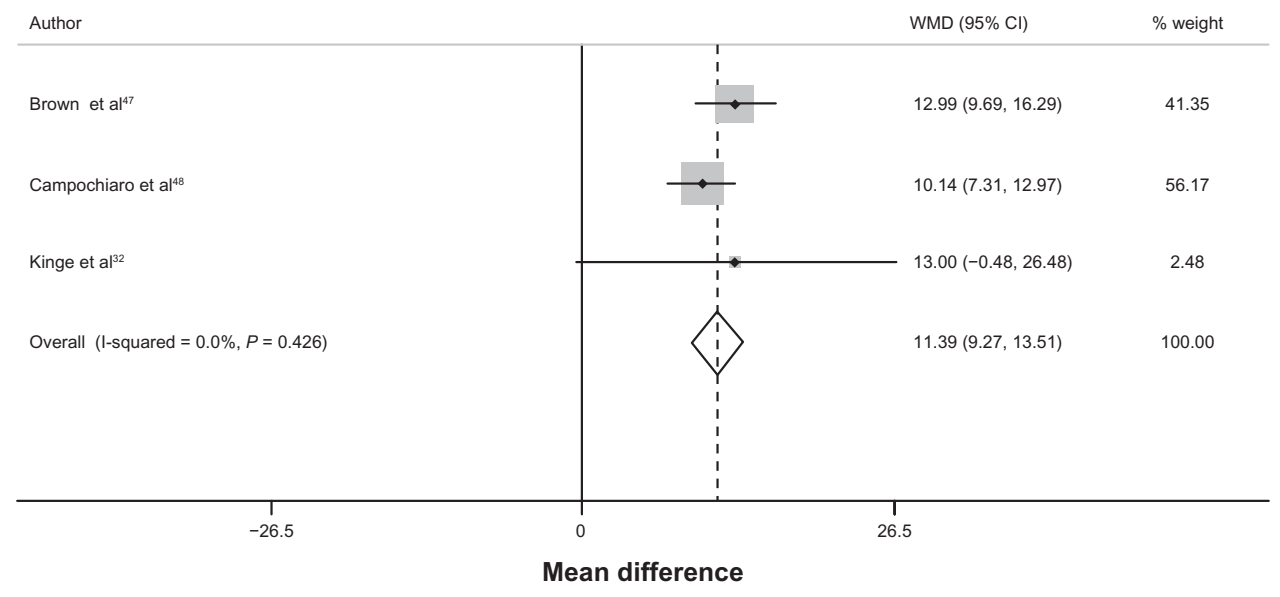

Figure 3 Forest plot of unstandardized mean difference of visual acuity between ranibizumab and sham in retinal vein occlusion. Abbreviations: $\mathrm{Cl}$, confidence interval; USMD, unstandardized mean difference; WMD, weighted mean difference. 
with sham were 3.39 ETDRS letters ( $95 \%$ CI -10.55 to 17.33 ) and 8.00 ETDRS letters (95\% CI -5.26 to 21.26), respectively, as seen in Table 1 and Figure S5.

Regarding concerns of safety, the analysis examined the adverse events by pooling all data together from three clinical indications. Only the RRs of serious systemic adverse effects (defined as death or serious cardiovascular events such as acute myocardial infarction or stroke) and ocular adverse effects (defined as endophthalmitis, retinal detachment, or vitreous hemorrhage) from all three clinical indications were pooled. Figure S6A illustrates the pooled RR of serious adverse effects from eleven studies ${ }^{19-22,27-31,33,34}$ that compared the frequency of serious adverse events from bevacizumab and nonpharmacological interventions. The results shown in Figure S6A reveal that there is no clear evidence of the difference in serious systemic and ocular adverse effects among nonpharmaceutical interventions and bevacizumab, with pooled RRs of 1.02 (95\% CI 0.39 to 2.65). The results were similar when comparing the risk of serious adverse events resulting from the use of bevacizumab and ranibizumab. The pooled RRs illustrated in Figure S6B produced a result of 1.14 ( $95 \%$ CI 0.52 to 2.51 ), which means that patients receiving bevacizumab had a nonsignificantly higher risk (14\%) of suffering serious adverse events.

\section{Discussion}

The findings of this systematic review and meta-analysis indicate that the intravitreal administration of bevacizumab is superior to nonpharmaceutical treatments for AMD and DME but inconclusive for RVO, given the limited evidence. The study also failed to distinguish the differences in terms of VA improvement, reduction of CMT, and response to treatment between AMD and DME patients treated with bevacizumab and those treated with ranibizumab.

In summary, the study confirms the findings from prior systematic reviews on the treatment of AMD and DME, with a caveat being that the study only included results from the largest and latest clinical trials that compared the efficacy of bevacizumab and ranibizumab for AMD. ${ }^{25,35-39}$ It is also the first study directly to compare clinical outcomes between bevacizumab and ranibizumab, whereas previous studies only assessed the outcomes of bevacizumab or ranibizumab in comparison to nonpharmaceutical interventions.

However, this study does have some limitations. Firstly, a sensible conclusion cannot be reached regarding the safety profiles of these two drugs, since incidences of serious adverse effects are extremely low. The results from the Comparison of Age-Related Macular Degeneration Treatment Trails
(CATT) conducted in the US on 1185 AMD patients show similar rates of mortality, myocardial infarction, and strokes for patients receiving either bevacizumab or ranibizumab; however, the proportion of patients with serious adverse effects which resulted in hospitalization was higher among those receiving bevacizumab than those being treated with ranibizumab. ${ }^{25}$ The investigators of the CATT study noted that the difference in serious adverse effects may be due to an imbalance in the baseline health status of the sample populations between the case-study and control groups. Secondly, due to the diversity in the reporting of VA using ETDRS, LogMAR, and Snellen fraction, a conversion method developed by Gregori et al ${ }^{40}$ to convert all VA outcomes to ETDRS was used. Lastly, this study focused only on clinical outcomes and not on the economic dimension. Raftery et a ${ }^{41}$ recently conducted economic modeling to estimate the incremental cost-effectiveness ratio of ranibizumab compared to bevacizumab in the UK. They concluded that ranibizumab will be cost-effective only if it is at least 2.5 times more efficacious than bevacizumab or bevacizumab has more than double the adverse effects of ranibizumab. ${ }^{41}$

\section{Policy implications in Thailand}

The preliminary findings of this study were presented on March 28, 2012 in a consultation meeting with stakeholders, including ophthalmologists, academicians, and representatives from the Thai FDA and pharmaceutical industry. Recommendations derived from the meeting include (1) price negotiation with relevant actors within the pharmaceutical industry on ranibizumab; (2) the inclusion of bevacizumab in the NLEM for the treatment of AMD, DME, and RVO if the price negotiation failed to result in equitable prices for both drugs; and (3) the development of a system for monitoring the serious adverse effects of bevacizumab if it is included in the NLEM, as well as to ensure the early withdrawal of the drug if the monitoring system detects any serious problems.

The findings and the above recommendations were reported to the subcommittee on April 24, 2012. After extensive discussion among its members, the subcommittee decided to endorse the use of bevacizumab for the treatment of AMD and DME, but not for RVO. ${ }^{42}$ This is due to inadequate evidence to support the use of bevacizumab for RVO. The subcommittee also recommended that all public health plans establish a national registry for health facilities, clinical experts, and patients in order to monitor the drug's safety and effectiveness. It is expected that by 2013, there will be 39,000 AMD patients and 110,250 DME patients receiving bevacizumab treatment. 
This is not the first time that the subcommittee has endorsed the use of off-license medication in the NLEM. Issued in 2009, the most recent such recommendation was to endorse the use of intravenous immunoglobulin for the treatment of myasthenia gravis, acute exacerbation, or myasthenic crisis. ${ }^{43}$ The reason for this is that the National Drug Committee allows the NLEM to include off-license medications if there is strong evidence that the safety, efficacy/ effectiveness, and/or efficiency support the use of off-license medications. In this case, these two drugs were developed by the same company - Genentech - although Roche holds the license for bevacizumab and Novartis holds the license for ranibizumab in Thailand. ${ }^{44}$ However, there is not enough of an incentive for Roche to license the cheaper drug for the treatment of macular diseases. Although the use of offlicense medication is not legally prohibited in Thailand, clinical experts may feel pressured to use bevacizumab even if it has not been authorized by a national body, given the fact that the more expensive licensed drug is available in the market. This could lead to two negative outcomes for clinical experts, as they may be sued (1) for prescribing a more expensive medication to the patient when it is the patient's right to receive the cheaper treatment to cure the same disease, or (2) for the potential unforeseen incidents off-license medications may cause. Therefore, the inclusion of bevacizumab in the NLEM may elevate such pressure in the short term. The safety profile of bevacizumab for the treatment of macular diseases remains to be seen, and further evaluation is therefore recommended.

To the best of our knowledge, the use of bevacizumab for the treatment of macular diseases remains off-label in all countries including Thailand. Decision-makers and clinicians are facing a very challenging choice of whether to adopt the more expensive ranibizumab, approve the use of off-labeled bevacizumab, or leave this issue to the private market. The last approach may lead to inequitable access to essential treatment for patients with these macular diseases, as most of the patients, especially in developing settings, will not be able to afford ranibizumab and clinicians may be reluctant to prescribe off-label bevacizumab if has not been approved by a national authority. This paper provides information and alternative policy development that will be useful for other settings.

\section{Acknowledgments}

This study was supported by the Thai Health Promotion Foundation, the Health Systems Research Institute, the Bureau of Policy and Strategy of the Ministry of Public
Health, the Thailand Research Fund, and Thai Health-Global Link Initiative Project.

The authors would like to thank Dr Suwit Wibulpolprasert, Prof Visanu Thamlikitkul, and members of the Thai Retina Society, chaired by Dr Paisan Ruamviboonsuk, for their valuable comments and support. The authors are grateful for data extraction from Dr Chavakij Bhoomibunchoo. This study was supported by the Thai Health Promotion Foundation, the Health Systems Research Institute, the Bureau of Policy and Strategy of the Ministry of Public Health, the Thailand Research Fund, and Thai Health-Global Link Initiative Project.

\section{Disclosure}

The authors report no conflicts of interest in this work.

\section{References}

1. Mohara A, Youngkong S, Pérez Velasco R, et al. Using health technology assessment for informing coverage decisions in Thailand. J Comp Eff Res. 2012;1(2):137-146.

2. Tarn YH, Hu S, Kamae I, et al. Health-care systems and pharmacoeconomic research in Asia-Pacific region. Value Health. 2008;11 Suppl 1: S137-S155.

3. Jirawattanapisal T, Kingkaew P, Lee TJ, Yang MC. Evidence-based decision-making in Asia-Pacific with rapidly changing healthcare systems: Thailand, South Korea, and Taiwan. Value Health. 2009;12 Suppl 3:S4-S11.

4. Tantivess S, Teerawattananon Y, Mills A. Strengthening costeffectiveness analysis in Thailand through the establishment of the health intervention and technology assessment program. Pharmacoeconomics. 2009;27(11):931-945.

5. Moshfeghi AA, Rosenfeld PJ, Puliafito CA, et al. Systemic bevacizumab (Avastin) therapy for neovascular age-related macular degeneration: twenty-four-week results of an uncontrolled open-label clinical study. Ophthalmology. 2006;113(11):2002.e1-2002.e12.

6. Rosenfeld PJ, Brown DM, Heier JS, et al. Ranibizumab for neovascular age-related macular degeneration. $N$ Engl J Med. 2006;355(14): 1419-1431.

7. Rosenfeld PJ, Moshfeghi AA, Puliafito CA. Optical coherence tomography findings after an intravitreal injection of bevacizumab (avastin) for neovascular age-related macular degeneration. Ophthalmic Surg Lasers Imaging. 2005;36(4):331-335.

8. Brown DM, Kaiser PK, Michels M, et al. Ranibizumab versus verteporfin for neovascular age-related macular degeneration. N Engl J Med. 2006;355(14):1432-1444.

9. Brown DM, Michels M, Kaiser PK, Heier JS, Sy JP, Ianchulev T. Ranibizumab versus verteporfin photodynamic therapy for neovascular age-related macular degeneration: two-year results of the ANCHOR study. Ophthalmology. 2009;116(1):57-65.e5.

10. Fung AE, Lalwani GA, Rosenfeld PJ, et al. An optical coherence tomography-guided, variable dosing regimen with intravitreal ranibizumab (Lucentis) for neovascular age-related macular degeneration. Am J Ophthalmol. 2007;143(4):566-583.

11. Rosenfeld PJ, Fung AE, Puliafito CA. Optical coherence tomography findings after an intravitreal injection of bevacizumab (avastin) for macular edema from central retinal vein occlusion. Ophthalmic Surg Lasers Imaging. 2005;36(4):336-339.

12. Jones G. Tracking demographic changes in Thailand and policy implications. In: Jones G, Im-em W, editors. Impact of Demographic Change in Thailand. Bangkok: Thai National Economic and Social Development Board and United Nations Population Funds; 2011. 
13. Jenchitr W, Ruamviboonsuk P, Sanmee A, Pokawattana N. Prevalence of age-related macular degeneration in Thailand. Ophthalmic Epidemiol. 2011;18(1):48-52.

14. Rogers S, McIntosh RL, Cheung N, et al. The prevalence of retinal vein occlusion: pooled data from population studies from the United States, Europe, Asia, and Australia. Ophthalmology. 2010;117(2):313-319.e1.

15. Yau JW, Rogers SL, Kawasaki R, et al. Global prevalence and major risk factors of diabetic retinopathy. Diabetes Care. 2012;35(3):556-564

16. Campbell RJ, Dhalla IA, Gill SS, Bell CM. Implications of "not me" drugs for health systems: lessons from age related macular degeneration. BMJ. 2012;344:e2941.

17. Torjesen I. Novartis takes legal action over trusts' advice to use bevacizumab for wet AMD. BMJ. 2012;344:e2959.

18. Torjesen I. Why using Avastin for eye disease is so difficult. BMJ. 2012;344:e3012.

19. Bashshur ZF, Schakal A, Hamam RN, El Haibi CP, Jaafar RF, Noureddin BN. Intravitreal bevacizumab vs verteporfin photodynamic therapy for neovascular age-related macular degeneration. Arch Ophthalmol. 2007;125(10):1357-1361.

20. Lazic R, Gabric N. Verteporfin therapy and intravitreal bevacizumab combined and alone in choroidal neovascularization due to age-related macular degeneration. Ophthalmology. 2007;114(6):1179-1185.

21. Parodi MB, Iacono P, Papayannis A, Sheth S, Bandello F. Laser photocoagulation, photodynamic therapy, and intravitreal bevacizumab for the treatment of juxtafoveal choroidal neovascularization secondary to pathologic myopia. Arch of Ophthalmol. 2010;128(4):437-442.

22. Sacu S, Michels S, Prager F, et al. Randomised clinical trial of intravitreal Avastin vs photodynamic therapy and intravitreal triamcinolone: long-term results. Eye (Lond). 2009;23(12):2223-2227.

23. Biswas P, Sengupta S, Choudhary R, Home S, Paul A, Sinha S Comparative role of intravitreal ranibizumab versus bevacizumab in choroidal neovascular membrane in age-related macular degeneration. Indian J Ophthalmol. 2011;59(3):191-196.

24. Gharbiya M, Giustolisi R, Allievi F, et al. Choroidal neovascularization in pathologic myopia: intravitreal ranibizumab versus bevacizumab a randomized controlled trial. Am J Ophthalmol. 2010;149(3): 458.e1-464.e1.

25. Martin DF, Maguire MG, Ying GS, Grunwald JE, Fine SL, Jaffe GJ. Ranibizumab and bevacizumab for neovascular age-related macular degeneration. N Engl J Med. 2011;364(20):1897-1908.

26. Subramanian ML, Abedi G, Ness S, et al. Bevacizumab vs ranibizumab for age-related macular degeneration: 1-year outcomes of a prospective, double-masked randomised clinical trial. Eye (Lond). 2010;24(11):1708-1715.

27. Michaelides M, Kaines A, Hamilton RD, et al. A prospective randomized trial of intravitreal bevacizumab or laser therapy in the management of diabetic macular edema (BOLT study) 12-month data: report 2. Ophthalmology. 2010;117(6):1078.e2-1086.e2.

28. Scott IU, Edwards AR, Beck RW, et al. A phase II randomized clinical trial of intravitreal bevacizumab for diabetic macular edema. Ophthalmology. 2007;114(10):1860-1867.

29. Soheilian M, Ramezani A, Obudi A, et al. Randomized trial of intravitreal bevacizumab alone or combined with triamcinolone versus macular photocoagulation in diabetic macular edema. Ophthalmology. 2009;116(6):1142-1150.

30. Faghihi H, Roohipoor R, Mohammadi SF, et al. Intravitreal bevacizumab versus combined bevacizumab-triamcinolone versus macular laser photocoagulation in diabetic macular edema. Eur J Ophthalmol. 2008;18(6):941-948

31. Solaiman KA, Diab MM, Abo-Elenin M. Intravitreal bevacizumab and/or macular photocoagulation as a primary treatment for diffuse diabetic macular edema. Retina. 2010;30(10):1638-1645.
32. Kinge B, Stordahl PB, Forsaa V, et al. Efficacy of ranibizumab in patients with macular edema secondary to central retinal vein occlusion: results from the sham-controlled ROCC study. Am J Ophthalmol. 2010;150(3):310-314.

33. Russo V, Barone A, Conte E, Prascina F, Stella A, Noci ND. Bevacizumab compared with macular laser grid photocoagulation for cystoid macular edema in branch retinal vein occlusion. Retina. 2009;29(4):511-515.

34. Tufail A, Patel PJ, Egan C, et al. Bevacizumab for neovascular age related macular degeneration (ABC Trial): multicentre randomised double masked study. BMJ. 2010;340:c2459.

35. Andriolo RB, Puga ME, Belfort Junior R, Atallah AN. Bevacizumab for ocular neovascular diseases: a systematic review. Sao Paulo Med J. 2009;127(2):84-91.

36. Schmucker C, Ehlken C, Hansen LL, Antes G, Agostini HT, Lelgemann M. Intravitreal bevacizumab (Avastin) vs ranibizumab (Lucentis) for the treatment of age-related macular degeneration: a systematic review. Curr Opin Ophthalmol. 2010;21(3):218-226.

37. Schouten JS, La Heij EC, Webers CA, Lundqvist IJ, Hendrikse F. A systematic review on the effect of bevacizumab in exudative agerelated macular degeneration. Graefes Arch Clin Exp Ophthalmol. 2009;247(1):1-11.

38. Yilmaz T, Cordero-Coma M, Gallagher MJ, Teasley LA. Systematic review of intravitreal bevacizumab injection for treatment of primary diabetic macular oedema. Acta Ophthalmol. 2011;89(8):709-717.

39. Goyal S, Lavalley M, Subramanian ML. Meta-analysis and review on the effect of bevacizumab in diabetic macular edema. Graefes Arch Clin Exp Ophthalmol. 2011;249(1):15-27.

40. Gregori NZ, Feuer W, Rosenfeld PJ. Novel method for analyzing Snellen visual acuity measurements. Retina. 2010;30(7):1046-1050.

41. Raftery J, Clegg A, Jones J, Tan SC, Lotery A. Ranibizumab (Lucentis) versus bevacizumab (Avastin): modelling cost effectiveness. $\mathrm{Br} J$ Ophthalmol. 2007;91(9):1244-1246.

42. Subcommittee for Development of the National List of Essential Medicines. Agenda for "A systematic review of bevacizumab for macular diseases" Conducted by HITAP Research. Nonthaburi: Food and Drug Administration, Ministry of Public Health, Thailand; 2012.

43. Bureau of Drug Control, Food and Drug Administration, Thailand. National List of Essential Medicines (NLEM). Available from: http://www.nlem.in.th. Accessed October 14, 2012.

44. Thai Food and Drug Administration. http://www.fda.moph.go.th/eng/ drug/index.stm.

45. Nguyen QD, Shah SM, Khwaja AA, et al. Two-year outcomes of the ranibizumab for edema of the macula in diabetes (READ-2) study. Ophthalmology. 2010;117(11):2146-2151.

46. Mitchell P, Bandello F, Schmidt-Erfurth U, et al. The RESTORE study: ranibizumab monotherapy or combined with laser versus laser monotherapy for diabetic macular edema. Ophthalmology. 2011;118(4):615-625.

47. Brown DM, Campochiaro PA, Singh RP, et al. Ranibizumab for macular edema following central retinal vein occlusion: six-month primary end point results of a phase III study. Ophthalmology. 2010;117(6): 1124.e1-1133.e1.

48. Campochiaro PA, Heier JS, Feiner L, et al. Ranibizumab for macular edema following branch retinal vein occlusion: six-month primary end point results of a phase III study. Ophthalmology. 2010;117(6): 1102.e1-1112.e1.

49. Moradian S, Faghihi H, Sadeghi B, et al. Intravitreal bevacizumab vs. sham treatment in acute branch retinal vein occlusion with macular edema: results at 3 months (Report 1). Graefes Arch Clin Exp Ophthalmol. 2011;249(2):193-200. 


\section{Supplementary materials Search strategy}

Medline and Scopus were searched until December 2011 in order to identify relevant studies. The reference lists of previous systematic reviews and included studies were reviewed in order to identify additional eligible studies.

\section{Selection of studies}

Two reviewers independently selected the identified studies based on titles and abstracts. Full articles were retrieved if a decision could not be made based on the titles and abstracts alone. Disagreements about selection studies were resolved by consensus with a third party.

\section{Inclusion criteria}

Randomized controlled trials were selected if they met all of the following criteria: (1) included at least one of these following study participants - AMD, DME, and RVO; (2) compared any pairs of the following interventions - bevacizumab, ranibizumab, photocoagulation, and sham; (3) measured the outcomes as VA or CMT; (4) allowed the retrieval of full articles and included sufficient data for pooling treatment-effect sizes, such as the number of participants who responded to treatment, mean, and SD of VA and CMT in each treatment group.

\section{Data extraction}

Data were extracted independently by two reviewers using standardized data-extraction methods. The author, year of publication, baseline characteristics of participants, number of participants, mean, and SD of the outcomes of interest were extracted. If there were inadequate outcomes in the report, the reviewers contacted the author of each study.

\section{Outcomes}

Outcomes of interest were VA, CMT measured in micromillimeters, and numbers of patients who responded to treatment, which was classified in each study. Three methods (ETDRS letter score, logMAR, and Snellen chart score) were used for quantifying VA. However, VA measured by logMar and Snellen chart scores were converted to ETDRS letter scores by using the equation proposed by Gregori et al, as follows. ${ }^{40}$

$$
\log M A R=-1 \times \log (\text { Snellen fraction })
$$

$$
\begin{gathered}
\text { Approximate ETDRS letters }=85+50 \times \log \\
(\text { Snellen fraction }) \\
0.02 \operatorname{LogMAR}=1 \text { ETDRS letter score }
\end{gathered}
$$

Various criteria were used to classify the definition of response to treatment, with improvement of $\geq 15$ letters of ETDRS being the most commonly used criterion, followed by improvement of $\geq 10$ letters of ETDRS and $\geq$ two lines of $\log$ Mar.

\section{Statistical analysis}

For direct meta-analysis and continuous outcomes, the number of patients, means, and SDs after receiving treatment or mean change (mean after minus before receiving treatment ) in each treatment group of VA and CMT were pooled using USMD. Heterogeneity between studies was assessed using $Q$ and $I^{2}$ statistics. If heterogeneity ( $P$-value $<0.1$ or $I^{2} \geq 25 \%$ ) was present, the random-effect model was applied; otherwise, the fixed-effect model was applied. For binary outcomes, the relative risks of response rate from each study were pooled to estimate summary-effect sizes by using the inverse-variance method. However, if heterogeneity was present, the randomeffect model was applied. Sources of heterogeneity were explored by fitting covariables (age, baseline VA and CMT) one by one in metaregression. If sources of heterogeneity were suggested by metaregression, a subgroup analysis according to those covariables was performed.

For indirect comparisons, a network meta-analysis was applied to assess the efficacy of all possible treatment options. For continuous outcomes, a linear regression model weighted with their inverse variances was used to estimate all treatment effects. Effects of the study were fitted as covariables in the model. For binary outcomes, individual patientlevel data were obtained by expanding the summary data using the "expand" command in Stata (StataCorp, College Station, TX). Treatment effects were considered in multilevel data analysis with a log-link function using the "xtpoisson" command. The coefficients of each treatment were used to estimate pooled relative risks and their $95 \%$ CIs for each treatment. All analyses were performed using Stata software version 12 . A two-sided test with $P<0.05$ was considered for statistical significance except for the heterogeneity test, where a one-sided test with $P<0.1$ was applied. 


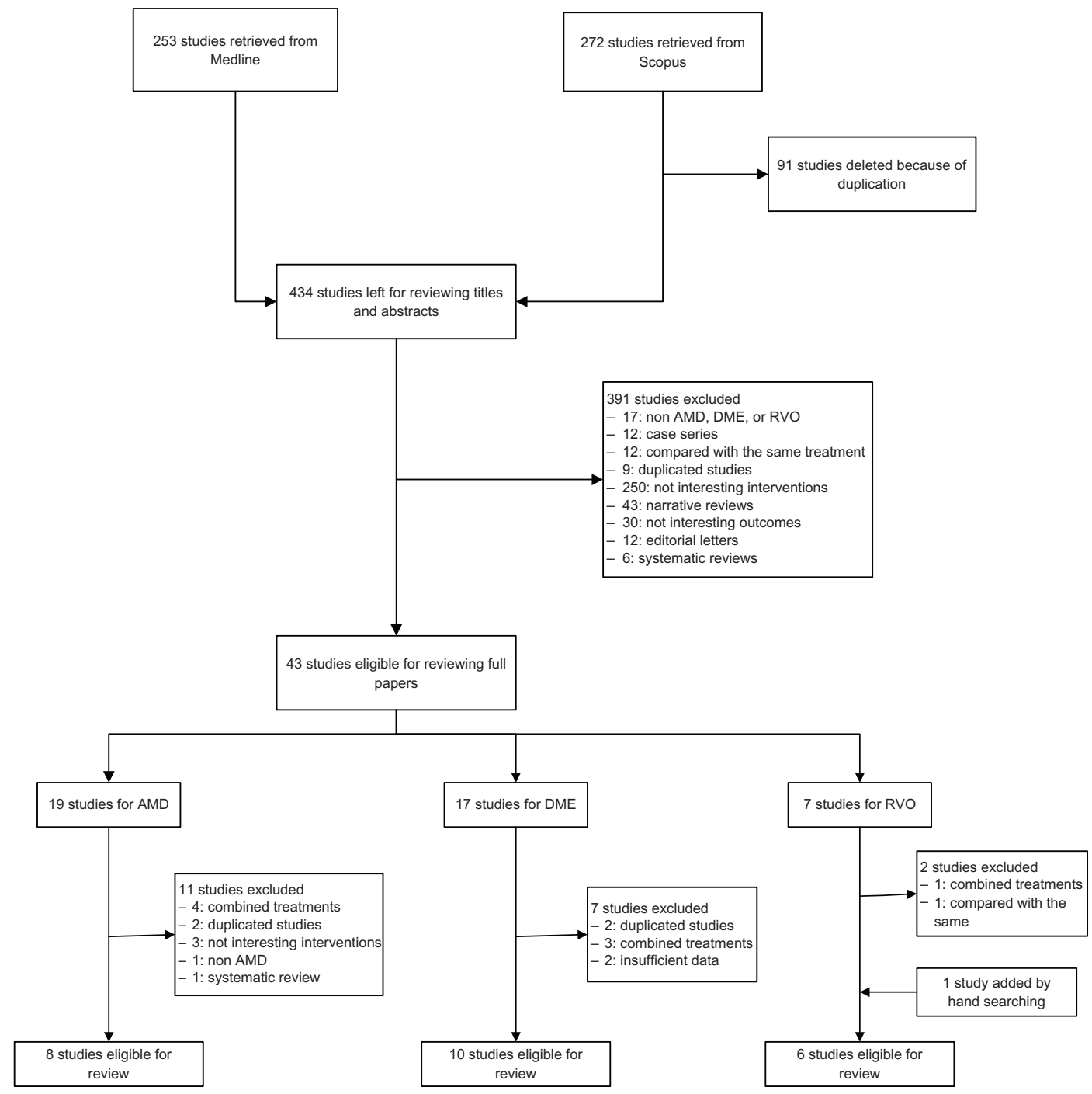

Figure SI Flowchart of study selection.

Abbreviations: AMD, age-related macular degeneration; DME, diabetic macular edema; RVO, retinal vein occlusion.

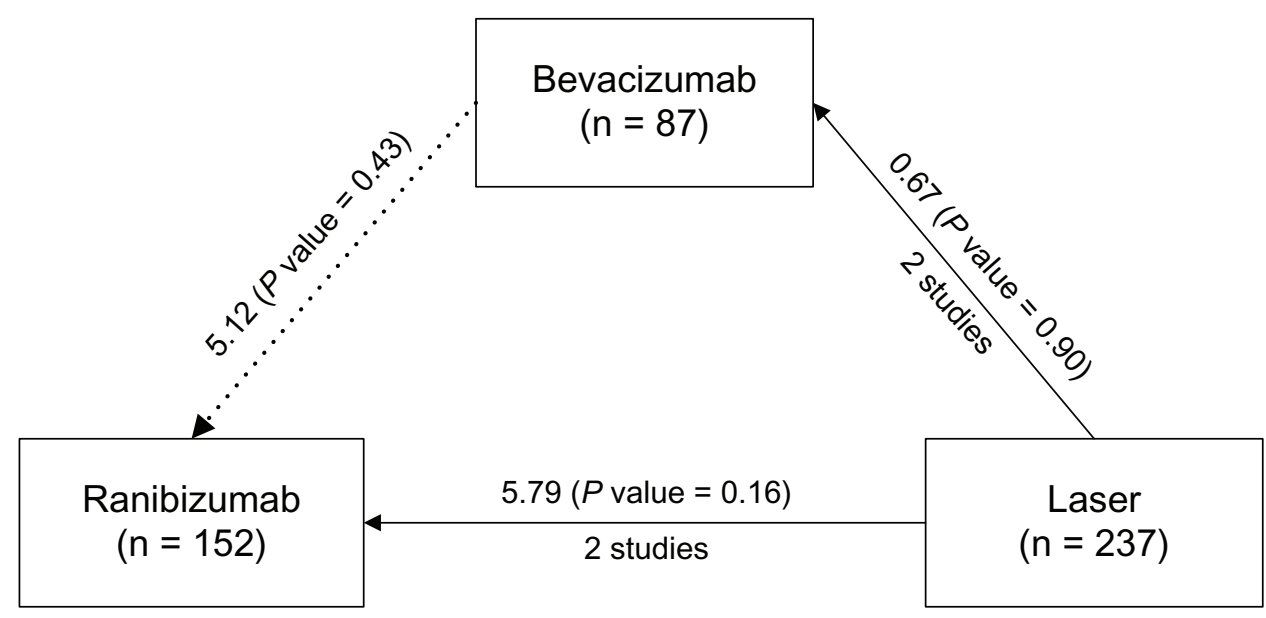

Figure S2 Network meta-analysis of treatment responsiveness in diabetic macular edema.

Notes: Lines represent treatment comparison, with heads and tails corresponding to interventions and comparators, respectively. Bold and dashed lines stand for direct and indirect comparisons, respectively. Numbers above the lines show relative risks of response to treatment, in which relative risk more than I indicates benefit of interventions. Numbers below the lines refer to number of studies for direct comparisons. 


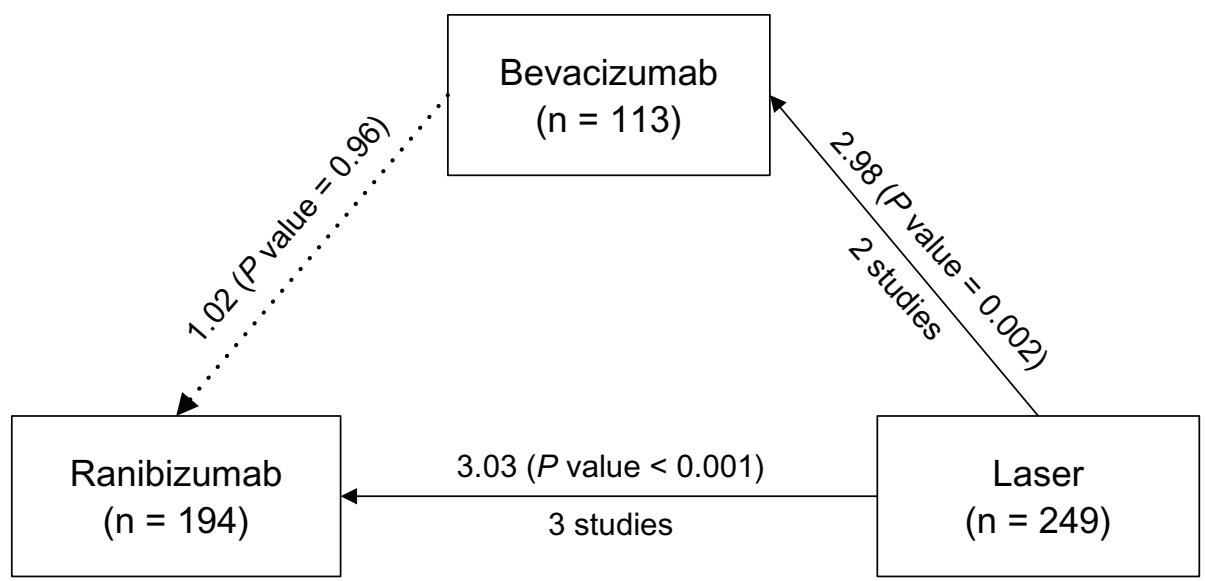

Figure S3 Network meta-analysis of visual acuity in diabetic macular edema.

Notes: Lines represent treatment comparison, with heads and tails corresponding to interventions and comparators, respectively. Bold and dashed lines stand for direct and indirect comparisons, respectively. Numbers above the lines show difference in visual acuity in Early Treatment Diabetic Retinopathy Study letter score, in which higher score indicates a higher benefit of interventions. Numbers below the lines refer to number of studies for direct comparisons.

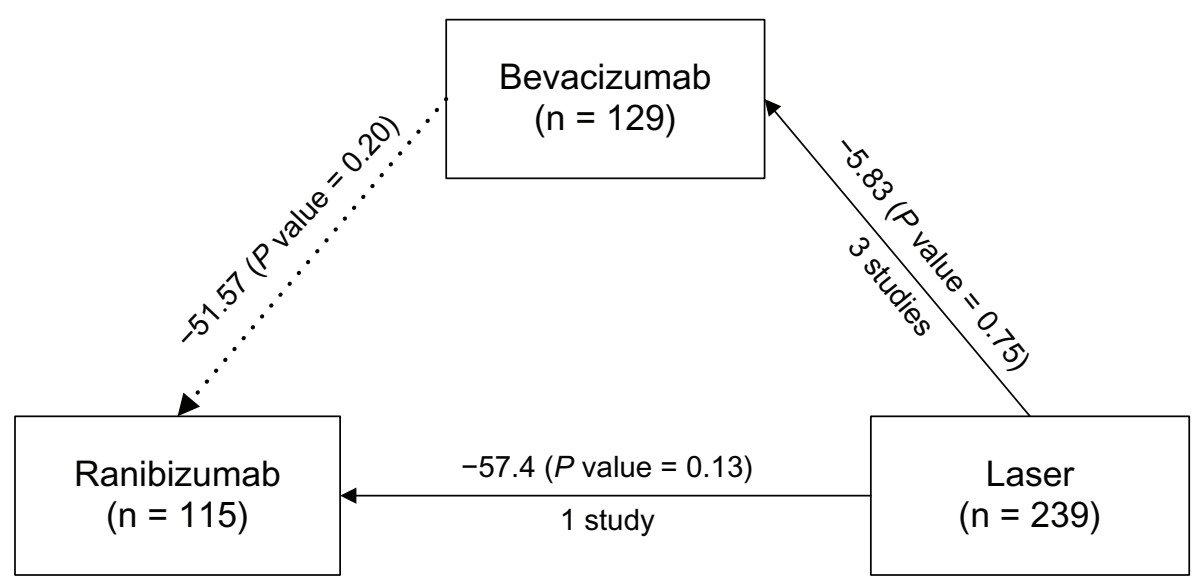

Figure S4 Network meta-analysis of central macular thickness in diabetic macular edema.

Notes: Lines represent treatment comparison, with heads and tails corresponding to interventions and comparators, respectively. Bold and dashed lines stand for direct and indirect comparisons, respectively. Numbers above the lines show difference in central macular thickness in $\mu \mathrm{m}$, in which lower score indicates a higher benefit of interventions. Numbers below the lines refer to number of studies for direct comparisons.

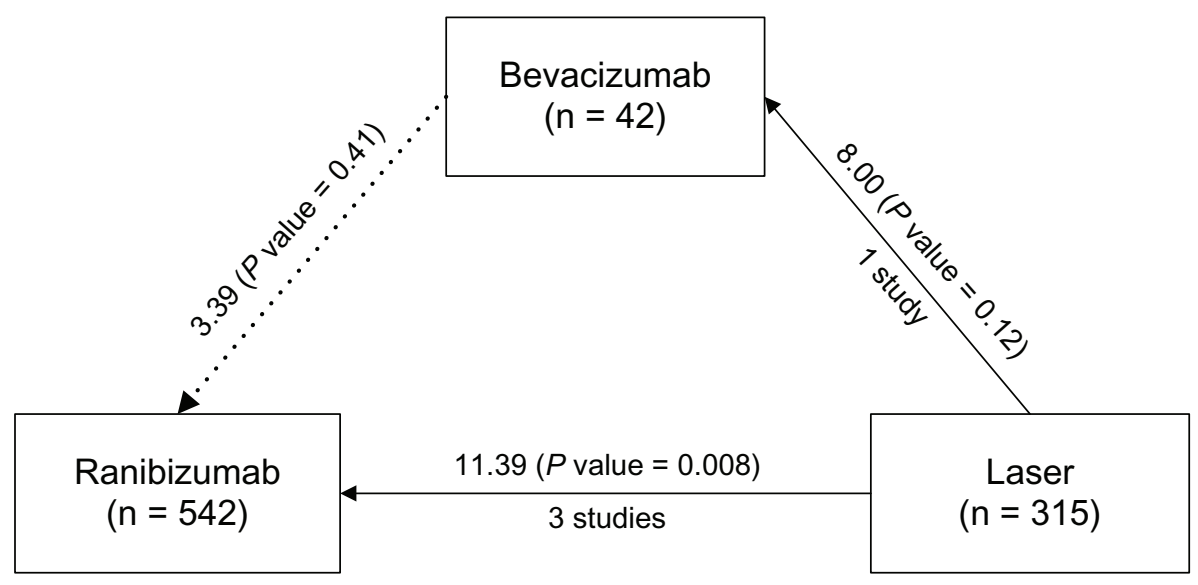

Figure S5 Network meta-analysis of visual acuity in retinal vein occlusion.

Notes: Lines represent treatment comparison, with heads and tails corresponding to interventions and comparators, respectively. Bold and dashed lines stand for direct and indirect comparisons, respectively. Numbers above the lines show difference in visual acuity in Early Treatment Diabetic Retinopathy Study letter score, in which higher score indicates a higher benefit of interventions. Numbers below the lines refer to number of studies for direct comparisons. 
A Bevacizumab vs nonpharmacological interventions

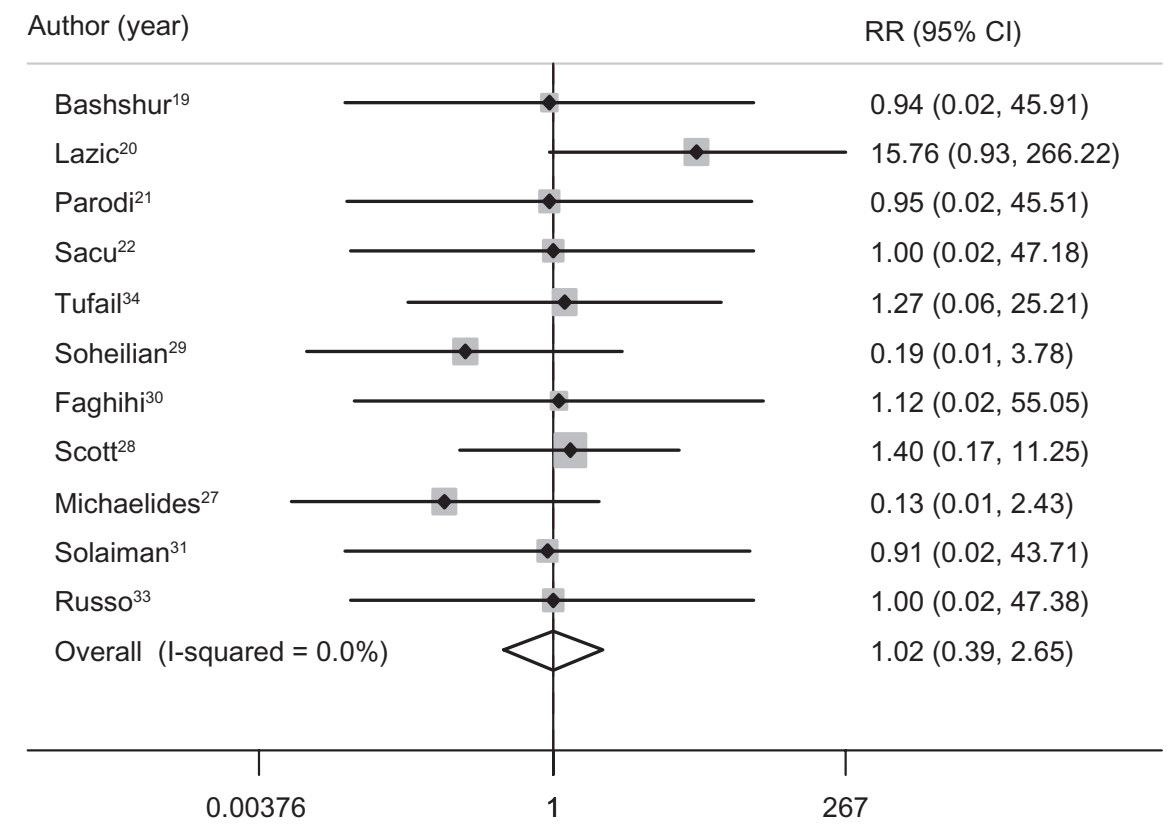

Relative risk

B

Bevacizumab vs Ranibizumab

Author (year)

$\operatorname{RR}(95 \% \mathrm{Cl})$

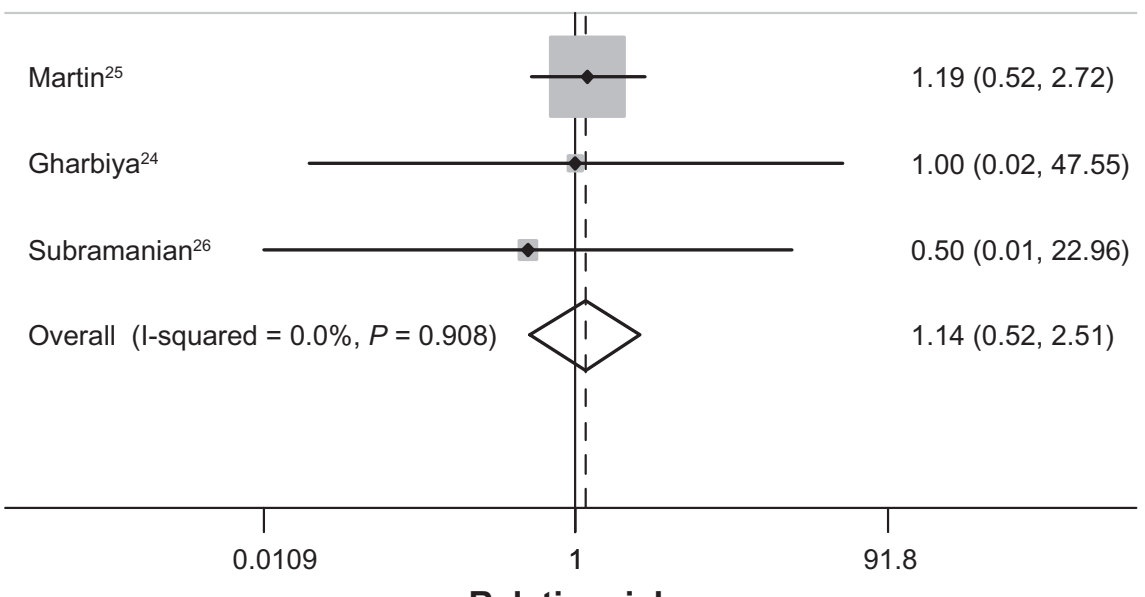

Relative risk

Figure S6 (A and B) Forest plot of relative risks of serious adverse effects of bevacizumab, ranibizumab, and nonpharmacological interventions in age-related macular degeneration, diabetic macular edema, and retinal vein occlusion. (A) Bevacizumab versus nonpharmacological interventions; (B) bevacizumab versus ranibizumab. 
Table SI Baseline characteristics of included studies on age-related macular degeneration

\begin{tabular}{|c|c|c|c|c|c|c|c|}
\hline Author & Year & Treatment & No of treatments & $\begin{array}{l}\text { Age } \\
\text { (years) }\end{array}$ & $\begin{array}{l}\text { VA } \\
\text { (ETDRS letters) }\end{array}$ & $\begin{array}{l}\text { CMT } \\
(\mu \mathrm{m})\end{array}$ & $\begin{array}{l}\text { Follow-up } \\
\text { (weeks) }\end{array}$ \\
\hline Bashshur et al ${ }^{19}$ & 2007 & IVB 2.5 mg vs PDT & 2.4 vs 2.3 & 75 & 47 & 353 & 24 \\
\hline Lazic and Gabric ${ }^{20}$ & 2007 & IVB I. 25 mg vs PDT vs IVB + PDT & NA & 75.7 & 46 & 353.4 & 12 \\
\hline Parodi et $\mathrm{a}^{21}$ & 2010 & IVB I.25 mg vs PDT vs laser & 3.8 vs 2.55 vs 1.17 & 49.98 & 71.89 & 234 & 104 \\
\hline Sacu et $\mathrm{al}^{22}$ & 2009 & IVB I mg vs PDT + IVTA 4 mg & 6.8 vs 1.9 & 78 & 48 & 341 & 52 \\
\hline Martin et $\mathrm{al}^{25}$ & 2011 & IVB $1.25 \mathrm{mg}$ vs IVR $0.5 \mathrm{mg}$ & 7.7 vs 6.9 & 78.85 & 60.95 & 459.5 & 52 \\
\hline Gharbiya et al ${ }^{24}$ & 2010 & IVB $1.25 \mathrm{mg}$ vs IVR $0.5 \mathrm{mg}$ & 2.8 vs 2.4 & 59.84 & 27.97 & 244 & 24 \\
\hline Biswas et $\mathrm{al}^{23}$ & 2011 & IVB I. $25 \mathrm{mg}$ vs IVR $0.5 \mathrm{mg}$ & 5.6 vs 4.3 & 63.9 & 57.52 & 286.4 & 72 \\
\hline Subramanian et $\mathrm{al}^{26}$ & 2010 & IVB $1.25 \mathrm{mg}$ vs IVR $0.5 \mathrm{mg}$ & 8 vs 4 & 78.59 & 34.23 & 304.89 & 52 \\
\hline
\end{tabular}

Abbreviations: VA, visual acuity; CMT, central macular thickness; ETDRS, early treatment diabetic retinopathy study; IVB, intravitreal bevacizumab; IVR, intravitreal ranibizumab; IVTA, intravitreal triamcinolone; NA, not applicable; PDT, photodynamic therapy.

Table S2 Baseline characteristics of included studies on diabetic macular edema

\begin{tabular}{|c|c|c|c|c|c|c|c|c|}
\hline Author & Year & Treatment & $\begin{array}{l}\text { Age } \\
\text { (years) }\end{array}$ & $\begin{array}{l}\text { VA (ETDRS } \\
\text { letters) }\end{array}$ & $\begin{array}{l}\text { CMT } \\
(\mu \mathrm{m})\end{array}$ & $\begin{array}{l}\text { Duration of DM } \\
\text { (years) }\end{array}$ & \% PDR & $\begin{array}{l}\text { Follow-up } \\
\text { (weeks) }\end{array}$ \\
\hline Scott et $\mathrm{al}^{28}$ & 2007 & IVB I.25 mg vs photocoagulation & 65 & 65 & 411 & NA & NA & 12 \\
\hline Faghihi et $\mathrm{a}^{30}$ & 2008 & IVB I. $25 \mathrm{mg}$ vs photocoagulation & 57 & 63 & 359.6 & NA & NA & 16 \\
\hline Soheilian et $\mathrm{al}^{29}$ & 2009 & IVB I. $25 \mathrm{mg}$ vs photocoagulation & 61.2 & 67 & 333.33 & 10.5 & 6 & 24 \\
\hline Michaelides et $\mathrm{al}^{27}$ & 2010 & IVB I.25 mg vs photocoagulation & 64.2 & 55 & 494.65 & 14 & NA & 52 \\
\hline Solaiman et $\mathrm{a}^{|3|}$ & 2010 & IVB I. $25 \mathrm{mg}$ vs photocoagulation & 57 & 58 & 455.88 & 18 & 34 & 24 \\
\hline Nguyen et $\mathrm{al}^{45}$ & 2010 & IVR $0.5 \mathrm{mg}$ vs photocoagulation & 62 & NA & 441.65 & NA & NA & 24 \\
\hline Mitchell et $\mathrm{al}^{46}$ & 2011 & IVR $0.5 \mathrm{mg}$ vs photocoagulation & 63.5 & 63 & 405 & NA & NA & 52 \\
\hline
\end{tabular}

Abbreviations: VA, visual acuity; CMT, central macular thickness; ETDRS, early treatment diabetic retinopathy study; DM, diabetes mellitus; IVB, intravitreal bevacizumab; IVR, intravitreal ranibizumab; NA, not applicable; PDR, proliferative diabetic retinopathy; VA, visual acuity.

Table S3 Baseline characteristics of included studies on retinal vein occlusion

\begin{tabular}{lllllll}
\hline Author & Year & Treatment & Age (years) & VA (ETDRS letters) & CMT ( $\mu$ m) & Follow-up (weeks) \\
\hline Brown et al $^{47}$ & 2010 & IVR 0.3, 0.5 mg vs sham & 67.57 & 48.3 & 685 & 24 \\
Campochiaro et al $^{48}$ & 2010 & IVR 0.3, 0.5 mg vs sham & 66 & 54.6 & 520.5 & 24 \\
Kinge et al $^{32}$ & 2010 & IVR 0.5 mg vs sham & 72 & 43 & 625 & 24 \\
Moradian et al $^{49}$ & 2011 & IVB I.25 mg vs sham & 57.6 & 38.45 & 525.17 & 12 \\
\hline
\end{tabular}

Abbreviations: CMT, central macular thickness; IVR, intravitreal ranibizumab; IVB, intravitreal bevacizumab; VA, visual acuity; ETDRS, early treatment diabetic retinopathy study.

Table S4 Treatment response rates of bevacizumab and photodynamic therapy for the treatment of age-related macular degeneration

\begin{tabular}{|c|c|c|c|c|c|c|c|}
\hline \multirow[t]{2}{*}{ Author } & \multirow[t]{2}{*}{ Year } & \multirow[t]{2}{*}{ Definition of treatment response } & \multicolumn{2}{|l|}{ IVB } & \multicolumn{2}{|l|}{ PDT } & \multirow[t]{2}{*}{ RR (95\% Cl) } \\
\hline & & & $\begin{array}{l}\text { No of } \\
\text { responses }\end{array}$ & $\begin{array}{l}\text { No of } \\
\text { nonresponses }\end{array}$ & $\begin{array}{l}\text { No of } \\
\text { responses }\end{array}$ & $\begin{array}{l}\text { No of } \\
\text { nonresponses }\end{array}$ & \\
\hline $\begin{array}{l}\text { Lazic and } \\
\text { Gabric }^{20}\end{array}$ & 2007 & 0.2 increase in logMAR & 1 & 53 & 0 & 50 & $2.78(0.12-66.75)$ \\
\hline $\begin{array}{l}\text { Bashshur } \\
\text { et al }{ }^{19}\end{array}$ & 2007 & $3 r d-$ line increase in Snellen fraction & 16 & 16 & 5 & 25 & $3.00(1.25-7.17)$ \\
\hline Sacu et $\mathrm{al}^{22}$ & 2009 & I5-letter increase in ETDRS score & 4 & 10 & 1 & 13 & $4.00(0.5 I-3 \mid .46)$ \\
\hline Parodi et $\mathrm{al}^{21}$ & 2010 & I5-letter increase in ETDRS score & 7 & 12 & 1 & 17 & $6.63(0.90-48.69)$ \\
\hline $\begin{array}{l}\text { Pooled RR } \\
(95 \% \mathrm{Cl})\end{array}$ & & & & & & & $3.44(1.67-7.1)$ \\
\hline
\end{tabular}

Abbreviations: $\mathrm{Cl}$, confidence interval; IVB, intravitreal bevacizumab; PDT, photodynamic therapy; RR, relative risk; ETDRS, Early Treatment Diabetic Retinopathy Study; logMAR, logarithm of the minimum angle of resolution. 
Table S5 Treatment response rates of ranibizumab and bevacizumab for the treatment of age-related macular degeneration

\begin{tabular}{|c|c|c|c|c|c|c|c|}
\hline \multirow[t]{2}{*}{ Author } & \multirow[t]{2}{*}{ Year } & \multirow[t]{2}{*}{ Definition of treatment response } & \multicolumn{2}{|l|}{ IVR } & \multicolumn{2}{|l|}{ IVB } & \multirow[t]{2}{*}{$\operatorname{RR}(95 \% \mathrm{Cl})$} \\
\hline & & & $\begin{array}{l}\text { No of } \\
\text { responses }\end{array}$ & $\begin{array}{l}\text { No of } \\
\text { nonresponses }\end{array}$ & $\begin{array}{l}\text { No of } \\
\text { responses }\end{array}$ & $\begin{array}{l}\text { No of } \\
\text { nonresponses }\end{array}$ & \\
\hline Martin et $\mathrm{a}^{25}$ & 2011 & I5-letter increase in ETDRS score & 71 & 214 & 76 & 195 & $0.89(0.67-1.17)$ \\
\hline $\begin{array}{l}\text { Gharbiya } \\
\text { et a }{ }^{24}\end{array}$ & 2010 & I5-letter increase in ETDRS score & 9 & 7 & 10 & 6 & $0.90(0.5 \mathrm{I}-\mathrm{I} .60)$ \\
\hline Biswas et $\mathrm{al}^{23}$ & 2011 & I5-letter increase in ETDRS score & 7 & 47 & 3 & 47 & $2.15(0.59-7.90)$ \\
\hline $\begin{array}{l}\text { Subramanian } \\
\text { et } \mathrm{a}^{26}\end{array}$ & 2009 & I5-letter increase in ETDRS score & 1 & 6 & 5 & 10 & $0.43(0.05-3.01)$ \\
\hline $\begin{array}{l}\text { Pooled RR } \\
(95 \% \mathrm{Cl})\end{array}$ & & & & & & & $0.91(0.7 I-1.16)$ \\
\hline
\end{tabular}

Abbreviations: $\mathrm{Cl}$, confidence interval; IVB, intravitreal bevacizumab; PDT, photodynamic therapy; RR, relative risk; ETDRS, Early Treatment Diabetic Retinopathy Study.

Table S6 Mean change of visual acuity and central macular thickness after receiving ranibizumab and bevacizumab for the treatment of age-related macular degeneration

\begin{tabular}{|c|c|c|c|c|c|c|c|}
\hline \multirow[t]{2}{*}{ Author } & \multirow[t]{2}{*}{ Year } & \multicolumn{3}{|l|}{ IVR } & \multicolumn{3}{|l|}{ IVB } \\
\hline & & $\mathbf{n}$ & Mean & SD & $\mathbf{n}$ & Mean & SD \\
\hline \multicolumn{8}{|c|}{ VA (ETDRS letter score) } \\
\hline Martin et $\mathrm{a}^{25}$ & 2011 & 285 & 6.80 & 13.10 & 271 & 5.90 & 15.70 \\
\hline Gharbiya et a $\left.\right|^{24}$ & 2010 & 16 & $|7.3|$ & 11.10 & 16 & 15.87 & 8.41 \\
\hline Biswas et $\mathrm{al}^{23}$ & 2011 & 54 & 3.56 & 8.90 & 50 & 3.96 & 8.36 \\
\hline Subramanian et $\mathrm{a}^{26}$ & 2010 & 7 & 6.29 & 13.74 & 15 & 7.53 & 15.32 \\
\hline USMD (95\% Cl) & & & $0.49(95 \% \mathrm{Cl},-\mathrm{I} .37$ to 2.34$)$ & & & & \\
\hline \multicolumn{8}{|l|}{ CMT $(\mu \mathrm{m})$} \\
\hline Martin et $\mathrm{a}^{25}$ & 2011 & 285 & -168.0 & 186.00 & 271 & -152.00 & 178.00 \\
\hline Biswas et $\mathrm{a}^{23}$ & 2011 & 54 & -44.7 & 66.56 & 50 & -37.96 & 55.33 \\
\hline Subramanian et $\mathrm{a}^{26}$ & 2009 & 7 & -102.0 & 72.90 & 13 & -35.00 & 80.50 \\
\hline USMD (95\% Cl) & & & $-14.18(95 \% \mathrm{Cl},-32.06$ to 3.70$)$ & & & & \\
\hline
\end{tabular}

Abbreviations: $\mathrm{Cl}$, confidence interval; CMT, central macular thickness; IVB, intravitreal bevacizumab; IVR, intravitreal ranibizumab; SD, standard deviation; USMD, unstandardized mean difference; VA, visual acuity; ETDRS, Early Treatment Diabetic Retinopathy Study.

Table S7 Treatment response rates of bevacizumab and photocoagulation for the treatment of diabetic macular edema

\begin{tabular}{|c|c|c|c|c|c|c|c|}
\hline \multirow[t]{2}{*}{ Author } & \multirow[t]{2}{*}{ Year } & \multirow[t]{2}{*}{ Definition of treatment response } & \multicolumn{2}{|l|}{ IVB } & \multicolumn{2}{|c|}{ Photocoagulation } & \multirow[t]{2}{*}{ RR (95\% Cl) } \\
\hline & & & $\begin{array}{l}\text { No of } \\
\text { responses }\end{array}$ & $\begin{array}{l}\text { No of } \\
\text { nonresponses }\end{array}$ & $\begin{array}{l}\text { No of } \\
\text { responses }\end{array}$ & $\begin{array}{l}\text { No of } \\
\text { nonresponses }\end{array}$ & \\
\hline $\begin{array}{l}\text { Scott } \\
\text { et } \mathrm{a}^{28}\end{array}$ & 2007 & $\begin{array}{l}\text { Improving } \geq 15 \text { letters of ETDRS } \\
\text { letters }\end{array}$ & 8 & 60 & I & 18 & $2.24(0.30-16.78)$ \\
\hline $\begin{array}{l}\text { Soheilian } \\
\text { et a }{ }^{29}\end{array}$ & 2009 & $\begin{array}{l}\text { Improving } \geq 2 \text { lines of Snellen } \\
\text { fraction }\end{array}$ & 14 & 31 & 5 & 37 & $2.49(0.98-6.30)$ \\
\hline $\begin{array}{l}\text { Michaelides } \\
\text { et a }{ }^{27}\end{array}$ & 2010 & $\begin{array}{l}\text { Improving } \geq 15 \text { letters of ETDRS } \\
\text { letters }\end{array}$ & 5 & 37 & 2 & 36 & $2.26(0.47-10.98)$ \\
\hline Pooled RR & & & & & & & $2.40(1.14-5.05)$ \\
\hline
\end{tabular}

Abbreviations: $\mathrm{Cl}$, confidence interval; IVB, intravitreal bevacizumab; RR, relative risk; ETDRS, early treatment diabetic retinopathy study. 
Table S8 Mean visual acuity and central macular thickness after receiving bevacizumab and photocoagulation for the treatment of diabetic macular edema

\begin{tabular}{|c|c|c|c|c|c|c|c|}
\hline \multirow[t]{2}{*}{ Author } & \multirow[t]{2}{*}{ Year } & \multicolumn{3}{|c|}{ IVB } & \multicolumn{3}{|c|}{ Photocoagulation } \\
\hline & & $\mathbf{n}$ & Mean & SD & $\mathbf{n}$ & Mean & SD \\
\hline \multicolumn{8}{|c|}{ Visual acuity (ETDRS letters) } \\
\hline Faghihi et $\mathrm{al}^{30}$ & 2008 & 42 & 65.0 & 15.0 & 47 & 64.0 & 15.0 \\
\hline Soheilian et $\mathrm{al}^{29}$ & 2009 & 45 & 75.0 & 14.0 & 42 & 70.0 & 20.0 \\
\hline Michaelides et $\mathrm{al}^{27}$ & 2010 & 42 & 61.3 & 10.4 & 38 & 50.0 & 16.6 \\
\hline Solaiman et $\mathrm{al}^{31}$ & 2010 & 21 & 59.0 & 6.0 & 19 & 58.0 & 39.0 \\
\hline \multirow[t]{2}{*}{ USMD (95\% Cl) } & & & 5.44 & & & & \\
\hline & & & $(95 \% \mathrm{Cl} 0.05$ to 10.83$)$ & & & & \\
\hline \multicolumn{8}{|c|}{ Central macular thickness $(\mu \mathrm{m})$} \\
\hline Faghihi et $\mathrm{al}^{30}$ & 2008 & 42 & 328 & 91 & 47 & 300 & 82 \\
\hline Soheilian et $\mathrm{a}^{29}$ & 2009 & 45 & 317 & 132 & 42 & 290 & 117 \\
\hline Michaelides et al ${ }^{27}$ & 2010 & 42 & 378 & 134 & 38 & 413 & 135 \\
\hline Solaiman et $\mathrm{al}^{31}$ & 2010 & 21 & 443 & 38 & 19 & 402 & 32 \\
\hline \multirow[t]{2}{*}{ USMD (95\% Cl) } & & & 23.61 & & & & \\
\hline & & & $(95 \% \mathrm{Cl}-2.78$ to 50.00$)$ & & & & \\
\hline
\end{tabular}

Abbreviations: $\mathrm{Cl}$, confidence interval; IVB, intravitreal bevacizumab; SD, standard deviation; USMD, unstandardized mean difference; ETDRS, Early Treatment Diabetic Retinopathy Study

Table S9 Mean change of visual acuity after receiving ranibizumab and sham for the treatment of retinal vein occlusion

\begin{tabular}{|c|c|c|c|c|c|c|c|}
\hline \multirow[t]{2}{*}{ Author } & \multirow[t]{2}{*}{ Year } & \multicolumn{3}{|l|}{ IVR } & \multicolumn{3}{|c|}{ Sham } \\
\hline & & $\mathbf{n}$ & Mean & SD & n & Mean & SD \\
\hline Brown et al ${ }^{47}$ & 2010 & 262 & 13.79 & 14.62 & 130 & 0.80 & 16.20 \\
\hline Campochiaro et $\mathrm{al}^{48}$ & 2010 & 265 & 17.44 & 14.62 & 132 & 7.30 & 13.00 \\
\hline Kinge et $\mathrm{a}^{32}$ & 2011 & 15 & 12.00 & 20.00 & 14 & -1.00 & 17.00 \\
\hline USMD (95\% Cl) & \multicolumn{7}{|c|}{ II. $39(95 \% \mathrm{Cl} 9.27$ to $\mid 3.5 \mathrm{I})$} \\
\hline
\end{tabular}

Abbreviations: $\mathrm{Cl}$, confidence interval; IVR, intravitreal ranibizumab; SD, standard deviation; USMD, unstandardized mean difference.

\section{Publish your work in this journal}

ClinicoEconomics \& Outcomes Research is an international, peerreviewed open-access journal focusing on Health Technology Assessment, Pharmacoeconomics and Outcomes Research in the areas of diagnosis, medical devices, and clinical, surgical and pharmacological intervention. The economic impact of health policy and health systems organization also constitute important areas of coverage. The manuscript management system is completely online and includes a very quick and fair peer-review system, which is all easy to use. Visit http://www.dovepress.com/testimonials.php to read real quotes from published authors 